\title{
A study on ship impacting a flexible crashworthy device for protecting bridge pier
}

\author{
Liming Yang a and Jun Liu \\ Mechanics and Material Science Research Center, Ningbo University, Ningbo, Zhejiang Province 315211, China
}

\begin{abstract}
As the accident of a vessel impacting a bridge pier will cause serious disaster, such as destroyed bridge, sinking ship and polluting environment, the technology and method to protect bridge pier from ship collision have been widely investigated recently. Due to the huge kinetic energy of large-tonnage ship and the short time duration in the collision, the studies involve impact mechanics. A developed flexible crashworthy device has been developed to protect bridges, which consists of an outer steel-periphery, an inner steel-periphery and the rubber coating SWRCs(soft elements) installed between them. When the SWRC crashworthy device is installed, the collision duration under low impact force is prolonged due to its high compliance, which results in the ship having enough time to turn its navigation direction and most of the remainder kinetic energy being carried off by the turned away ship. Consequently, both impact forces on the ship and on the bridge pier decrease markedly. This is the key reason as to why the SWRC crashworthy device can avoid the destruction of both the bridge and the ship. Based on our results of theoretical studies and numerical simulations, the present paper will propose an experiment-adopted a real ship to impact a flexible crashworthy device. The collision test has been performed 12 times with different speed, carrying capacity, and impact angle of the ship. After the experiments, the ship, flexible crashworthy device and the pier are not damaged. The experiments show that the flexible crashworthy device can turn away the impact ship, so that the ship moves along the outer part of the device, which reduces the ship impact force on the bridge pier obviously. It not only protects bridges but also avoids the damage to ships.
\end{abstract}

\section{Introduction}

As the accident of a vessel impacting a bridge pier will cause serious disaster, such as destroyed bridge, sinking ship and polluting environment, the technology and method to protect bridge pier from ship collision have been widely investigated recently [1]. Due to the huge kinetic energy of large-tonnage ship and the short time duration in the collision, the studies involve impact mechanics. The model experiments, the theoretical analyse and numerical simulations have attracted tremendous research interest in the last few decades [2-5]. However, the results obtained could not be accepted by bridge managements, due to the devices have not been undergone a impact test with a real ship.

Based on our results of theoretical studies and numerical simulations [2], a flexible crashworthy device to protect bridge pier against ship collision has been developed. The present paper will introduce an experiment: adopted a real ship to impact the flexible crashworthy device to validate its capability of protecting the bridge pier and the impacting ship.

\section{Flexible crashworthy device for protecting bridge pier}

\subsection{Structure and principle of the flexible crashworthy device}

Resent years, a flexible crashproof device has been created developed by authors [2], which essentially consists of

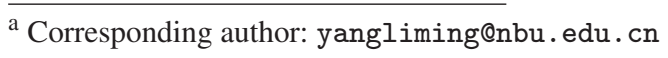

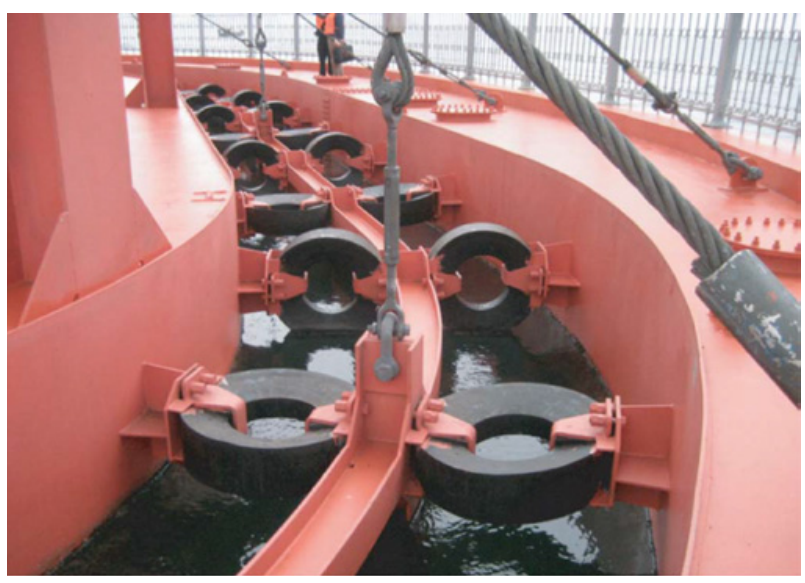

Figure 1. Structure of a flexible crashworthy device.

many steel-wire-rope coil (SWRC) connected in parallel and series. A developed flexible crashworthy device is shown in Fig. 1, which consists of an outer steel-periphery, an inner steel-periphery and the rubber coating SWRCs installed between them. The outer steel-periphery will be collided with a coming ship. Impacting force which bridge pier withstood will be buffered by SWRC.

When the flexible crashworthy device is installed, the collision duration under low impact force is prolonged due to its high compliance, which results in the ship having enough time to turn its navigation direction and most of the remainder kinetic energy (60-95\% depending on the actual incidence collision angle) being carried off by the turned away ship. Consequently, both impact forces on

This is an Open Access article distributed under the terms of the Creative Commons Attribution License 4.0, which permits unrestricted use, distribution, and reproduction in any medium, provided the original work is properly cited. 


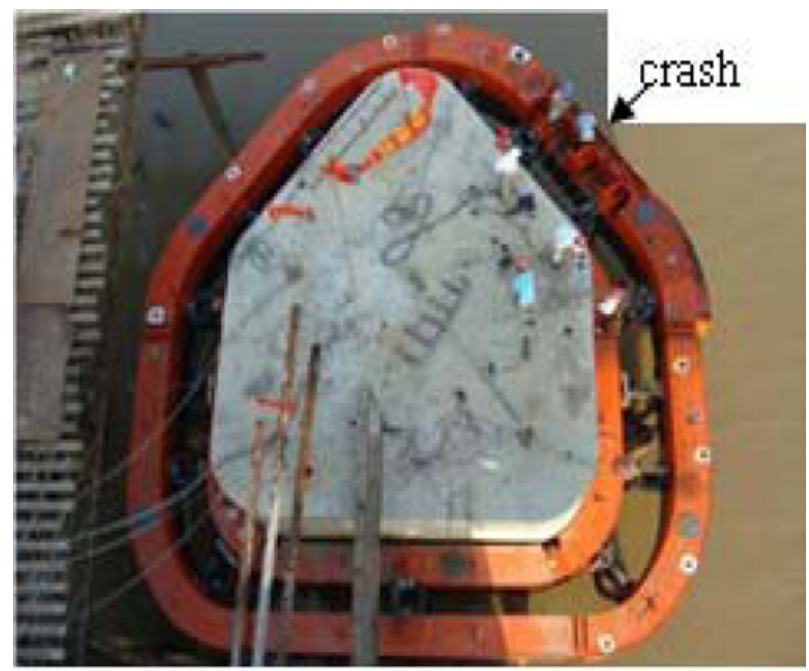

Figure 2. Flexible crashworthy device for test.

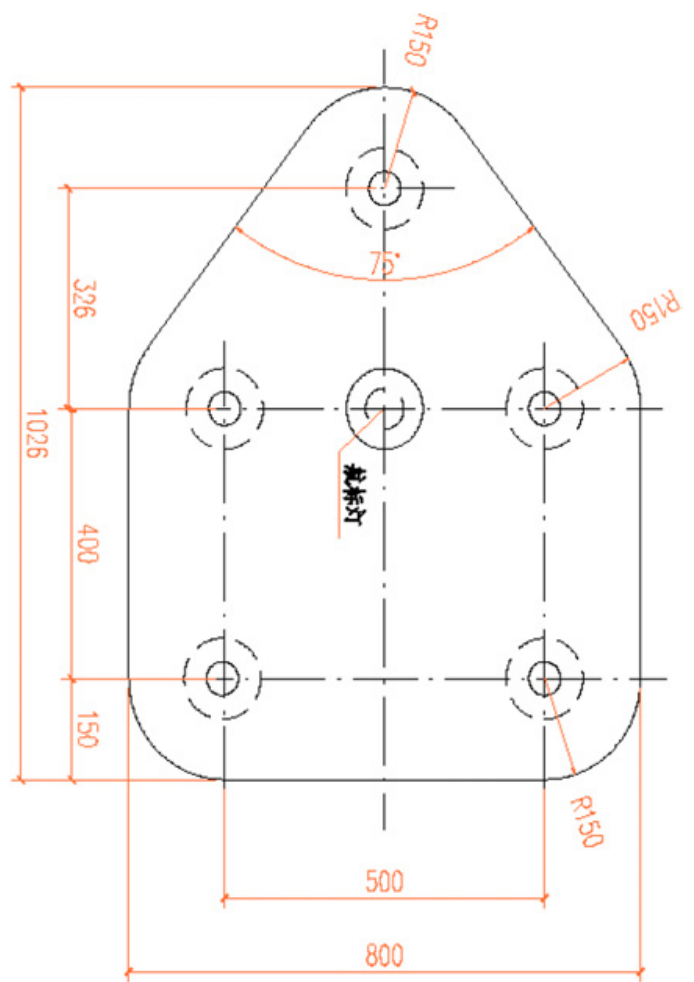

Figure 3. Bridge pier dimensions.

the ship and on the bridge pier decrease markedly. This is the key reason as to why the present SWRC crashworthy device can avoid the destruction of both the bridge and the ship. On the other hand, the stiffness of the outer steel-periphery is strong so that the ship collision cannot produce a deformation location and a localized instability.

\subsection{Flexible crashworthy device for test}

In order to test the validity and reliability of the developed bridge anti-ship collision flexible protection technology, in Ningbo Xiangshan White Pier Port the tests have been performed to use a real ship to impact the flexible crashworthy device which is shown in Fig. 2. The force sensors are installed between SWRC and inner-periphery,

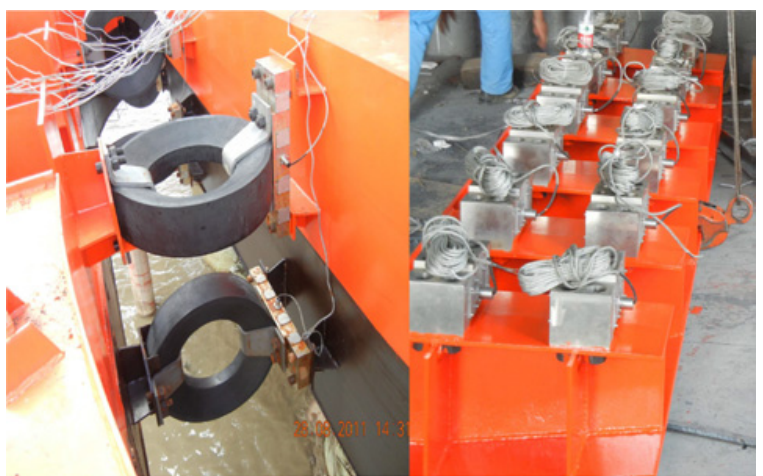

Figure 4. The force sensors are installed in the device.

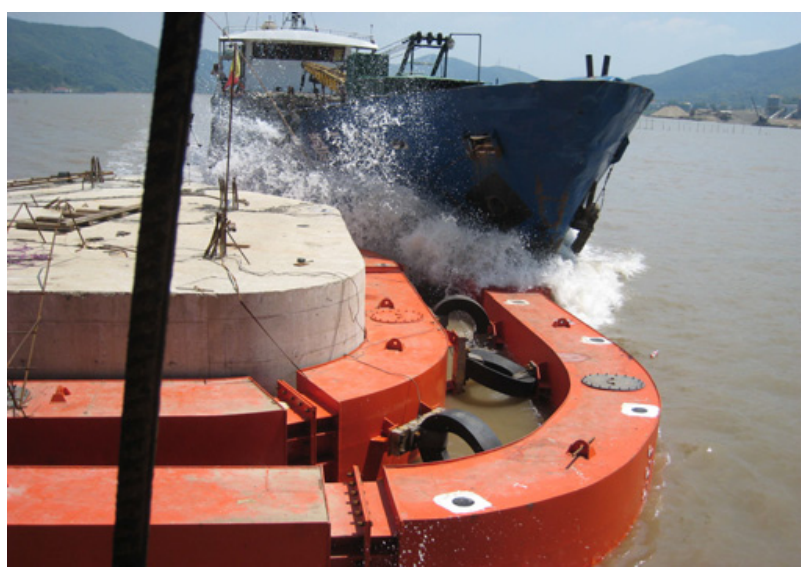

(a)

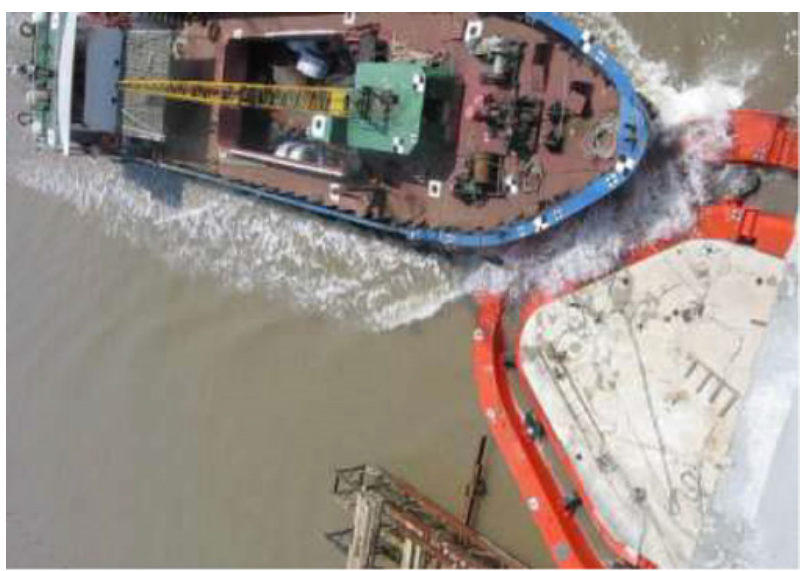

(b)

Figure 5. The collision experiments.

as well as the acceleration sensors are arranged in the experimental ship. The ship weight is 250 ton and its deadweight (dwt) is 400 ton. The track of the ship after impact has also been measured by high speed camera.

The detail dimension of the bridge pier is shown in Fig. 3. The device width is about $13.7 \mathrm{~m}$, length is about $14 \mathrm{~m}$ (Fig. 2). The structures of outer steel-periphery and inner steel-periphery are box shape. The device is floatable, so that its capability to protect the bridge pier cannot be affected by the tide. Figure 4 shows the force sensors are located in the device. 


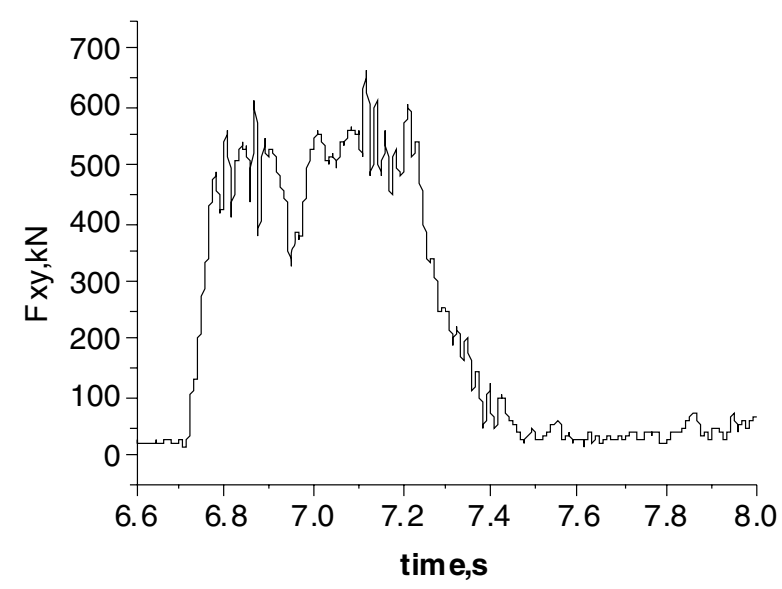

(a) Measurement

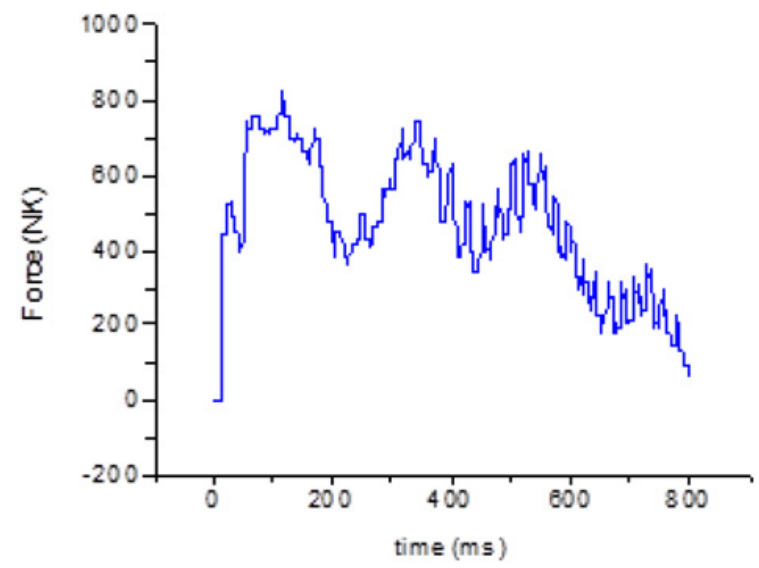

(b) Simulation

Figure 6. The curves of time-impact force in case 1.

\subsection{Collision experiments}

The collision test has been performed 12 times with different speed, carrying capacity, and impact angle of the ship. The ship speed is increased from $1 \mathrm{~m} / \mathrm{s}$ to $4 \mathrm{~m} / \mathrm{s}$. The range of ship weight is $250,000 \mathrm{~kg} \sim 400,000 \mathrm{~kg}$. The impact angle changed from $0^{\circ}$ to $26^{\circ}$. In the tests, the impact forces, the ship acceleration and the ship track are measured. Tests show that:

(1) The device can let ship turn its navigation direction and move along the outside of the outer steelperiphery (Fig. 5), even if the ship impact angle reached $26^{\circ}$.

(2) During impact, the ship almost keeps its constant speed. For the tests in which the ship impact angle is less than $5^{\circ}$, the speed only decreased $5 \%$ after impact. For the tests of ship impact angle is $26^{\circ}$, the speed decreased $20 \%$ after impact. The results means that the dissipation of ship kinetic energy is small during impacted.

(3) After the 12 experiments, the ship, flexible crashworthy device and the pier are all not damaged. It is found that the developed crashworthy device has the capability to protect the bridge pier and the impact ship.

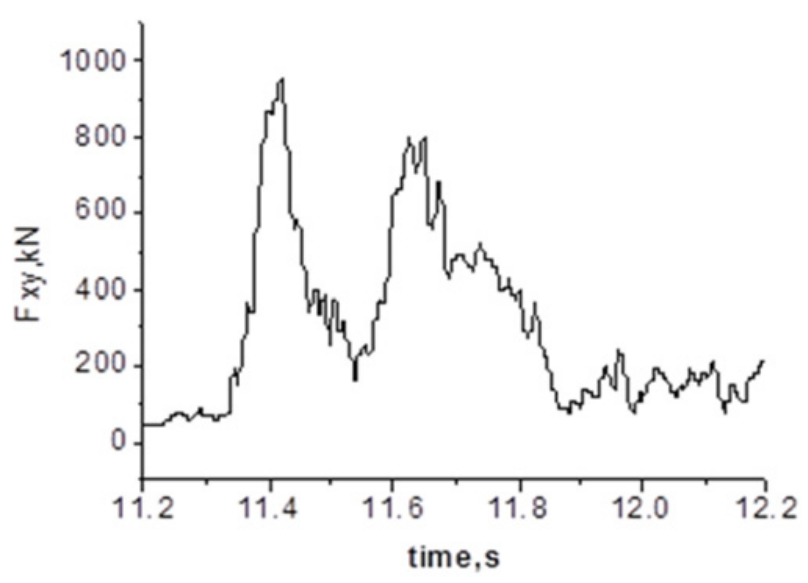

(a) Measurement

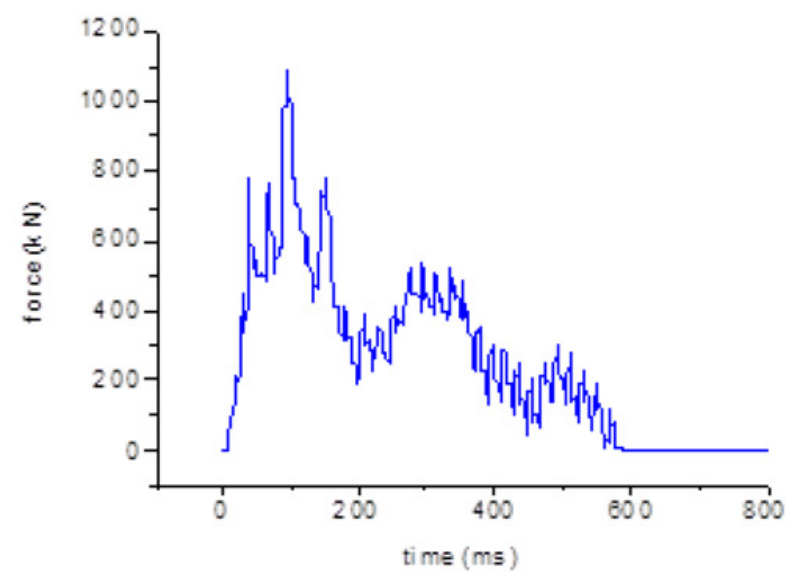

(b) Simulation

Figure 7. The curves of time-impact force in case 2.

Table 1. Conditions of calculation results compared to test data.

\begin{tabular}{|c|c|c|c|c|}
\hline $\begin{array}{c}\text { Ship } \\
\text { (ton) }\end{array}$ & $\begin{array}{c}\text { Shipht } \\
\text { speed } \\
(\mathrm{m} / \mathrm{s})\end{array}$ & $\begin{array}{c}\text { Ship } \\
\text { impact } \\
\text { angle }\end{array}$ & $\begin{array}{c}\text { Impact force } \\
\text { without } \\
\text { protecting } \\
\text { device } \\
\text { (ton) }\end{array}$ & $\begin{array}{c}\text { Impact } \\
\text { force with } \\
\text { protecting } \\
\text { device } \\
\text { (ton) }\end{array}$ \\
\hline 250 & 2.3 & $26^{\circ}$ & 270 & 65 \\
\hline 250 & 3.0 & $0^{\circ}$ & 160 & 65 \\
\hline 400 & 3.5 & $0^{\circ}$ & 230 & 100 \\
\hline
\end{tabular}

\subsection{Comparison with simulation}

The finite element software Ls-DYNA has been adapted to simulate the dynamic responses of the ship-bridge collision. In the finite element model, the bridge pier is assumed to be rigid, steel mechanical property is elasticplasticity, and the SWRC is modelled by a nonlinear visco-elastic body. The material parameters used are same as those shown in the reference [2]. Some numerical simulations and experimental results are shown below.

Case 1: the ship weight is $250,000 \mathrm{~kg}$, its speed is $2.3 \mathrm{~m} / \mathrm{s}$, and the ship impact angle is $26^{\circ}$. Figure $6(\mathrm{a})$ shows the measurement data, and Fig. 6(b) is numerical simulation results.

Case 2: the ship weight is $400,000 \mathrm{~kg}$, its speed is $3.5 \mathrm{~m} / \mathrm{s}$, and the ship impact angle is $0^{\circ}$. Figure $7(\mathrm{a})$ 
shows the measurement data, and Fig. 7(b) is numerical simulation results.

Compared above figures, it is found that the numerical simulation results are in reasonable agreement with the measurement results. The numerical simulation can be considered to be reliable and valid. Thus, the numerical simulation is used to calculate the impact force during a ship crashes a bridge pier without any protecting device. The results are shown in Table 1.

Table 1 shows that the flexible crashworthy device can decrease markedly contact force.

\section{Conclusion}

The experiments show that the flexible crashworthy device can turn away the impact ship, the ship moves along the outer side of the device, which reduces the ship impact force on the bridge pier obviously. It not only protects bridges but also avoids the damage to ships.
The support from the National Natural Science Foundation of China under its Key Project No. 11032001 is gratefully aknowledged.

\section{References}

[1] G. Y. Chen, L. L. Wang, L. M. Yang, M. D. Chen, The Protection Theory for Ship-Bridge Collisions and the Design of Crashworthy Devices (China Communications Press, 2014)

[2] L. L. Wang, L. M. Yang, D. J. Huang, Z. W. Zhang and G. Y. Chen, I. J. Impact Engn. 35, 895 (2008)

[3] D. Larry, P. E. Olson, Dynamic Bridge Substructure Evaluation and Monitoring. Report No. FHWARD-03-089, U.S. Federal Highway Administration, (2005)

[4] P. T. Pedersen, Marine Struct. 23, 241 (2010)

[5] F. Yang, L. M. Yang, Chinese J Solid Mech. 32, 399 (2011) 